\title{
Development and Evaluation of Pedal Thresher for Threshing of Rice
}

\author{
Dagninet Amare ${ }^{1}$, Negese Yayu ${ }^{2}$, Asmamaw Endeblihatu ${ }^{1}$ \\ ${ }^{1}$ Bahir Dar Agricultural Mechanization and Food Science Research Center, Bahir Dar, Ethiopia \\ ${ }^{2}$ Institute of Technology, Bahir Dar University, Bahir Dar, Ethiopia
}

Email address:

dagnnet@gmail.com (D. Amare)

To cite this article:

Dagninet Amare, Negese Yayu, Asmamaw Endeblihatu. Development and Evaluation of Pedal Thresher for Threshing of Rice. American Journal of Mechanics and Applications. Vol. 3, No. 4, 2015, pp. 27-32. doi: 10.11648/j.ajma.20150304.11

\begin{abstract}
Rice is becoming increasingly an important crop in Ethiopia. Owed to the post harvest losses, evaluation and demonstration of an imported pedal thresher was conducted. In addition, a proto type was developed using reverse engineering. Data was collected using structured data sheet and analyzed using descriptive statistics and parametric tests. Duncan and Tukey mean tests showed the absence of significant mean threshing output difference between the pedal type $(127.5 \mathrm{~kg} / \mathrm{hr})$ and the modified $(120 \mathrm{~kg} / \mathrm{hr})$ one. The result showed statistically different threshing output using these technologies as compared to the traditional method $(92 \mathrm{~kg} / \mathrm{hr})$. The financial analysis showed that an average Fogera farmer $(0.35$ ha rice land $)$ could thresh his annual rice yield within $9.25 \mathrm{hrs}$ and $8.68 \mathrm{hrs}$ using modified and pedal threshers with a cost reduction of ETB 320.58 compared to the traditional system. The low awareness of the farmers on the consequences and advantages of threshing on quality of rice and subsequently on preference and marketing resulted in low priority for adoption. Hence, large scale awareness creation activities should be done and the technology ought to be promoted widely in order to contribute for the government's aim as a millennium crop and benefit from the market opportunity reassuring in the country.
\end{abstract}

Keywords: Pedal Rice Thresher, Modified Thresher, Traditional Threshing, Duncan, Tukey Test

\section{Introduction}

The discovery of wild rice in the Fogera plain in the early 1970s was the basis for rice introduction in Ethiopia [1]. Rice is becoming one of the important staple foods and its production area has been increasing over the years in Fogera and other parts of Ethiopia [1] [2] [3]. The Fogera plain alone contributes $32 \%$ of the national rice production [4] [5].

Rice production and consumption is increasing owe to various reasons. The compatibility of rice for various traditional food recipes is one that surged its demand. Farmers use rice to prepare injera, bread and alcoholic drinks like Tela and Arekie. It is used as cash crop, source of feed (rice straw and bran) and house construction [1]. The country has vast suitable ecologies for rice production of about 30 million ha [6] in the rain fed system. The comparative advantage of producing rice due to the availability of huge and cheap rural labor is another opportunity for producing rice. The importance of rice as a food security crop, source of income and employment opportunity due to its relative high productivity as compared to other cereals is recognized by farmers. Rice is also considered as an optional crop by private investors who frequently request for improved varieties for different ecosystems [6].

National demands are not currently being satisfied by local production even if the trend is increasing. Even the local rice produce is low quality. The poor quality is due to fracturing and stickiness attributed to poor agronomic practices, postharvest handling [7] and low standard rice processing. In consequence, the government is spending large amounts of money on importing rice [8] [9]. In order minimize imports wise utilization of available produce is critical. Proper post harvest handling and avoidance of premature harvesting [1] are potential interventions. Pre mature harvesting and low quality production may continue at least in the short run owe to the production system in the areas that mostly follow double cropping systems. Hence, it is decisive to increase the production and improve market competitiveness' by proper post harvest management. Such initiatives if successful will contribute to achievement of national food security [9] and increase household income.

Rice has one of the highest post harvest losses among 
cereals. The issue of rice post-harvest management is nationally recognized [10]. Qualitative post harvest loss of rice could reach as much as $50 \%$ of the production [11]. The quantitative post harvest loss is between $10 \%$ and $22 \%$ in sub-Saharan Africa. Threshing losses account for 30\% of rice post harvest loss in Ghana [8]. The post harvest loss of rice in Fogera reaches $12.4 \%$ (12462 tones) of total production [12].

Reducing postharvest losses, among others, could help in reducing rice imports with its accompanied economic losses [8]. Traditional threshing methods trampling with animals and humans incur huge loss [7]. Increased rice production, inefficiency of manual threshing, seasonal drudgeries of women and children and subsequent losses require the introduction of improved threshing machines [13]. In the study area, promotion of this kind of technology is rationalized due to the need to lighten workloads owe to multiple cropping. Hence, demonstration and promotion of harvesting technologies is recommended in Fogera [1]. Concomitantly, Selection and promotion of rice threshers should consider threshing rate (reduce labor requirement and overall output), threshing loss (scattering, threshing and breakage losses), versatility (operating conditions like moisture content), power source, output quality, portability, ease of use (if it can be used most members like women), safety and purchase and running costs [14]. Based on this, a manual (human operated) rice thresher (hereafter referred as pedal) was imported from Japan for demonstration. A prototype (hereafter referred as modified) was also developed in the centre using reverse engineering. Hence, these two technologies were demonstrated along with the traditional system. The research activity thus aimed at evaluating, demonstrating and creating awareness on these threshers and collecting feedbacks on future promotion activities.

\section{Materials and Methods}

\subsection{Study Site Description}

This study was conducted in Fogera woreda of Amhara region, Ethiopia. Fogera is situated at $11^{\circ} 46$ to $11^{\circ} 59$ latitude north and $37^{\circ} 33$ to $37^{\circ} 52$ longitudes East with altitude ranges from 1774 to 2410 meters above sea level [1].

\subsection{Demonstration Sites}

Demonstration sites were selected purposively in the project area with Woreda agriculture offices. The demonstration sites Abua-kokit and Diba-Sefatra kebeles from Fogera Woreda. The technologies were also demonstrated in Shina Tsion kebele of Libo-Kemkem Woreda. Two (2) farmers research extension groups (FREGs) were established as a means for evaluation and promotion of the technologies though lateral extension system and feed backs collection. The pedal and modified rice threshers were demonstrated at the first and second years of the project respectively.

\subsection{Treatments}

\subsubsection{Traditional Rice Threshing}

Threshing rice in Fogera is done traditionally. The traditional threshing methods are beating by stick (Table 1) and animal trampling. Beating involves pounding shelves of rice crop on hard surface or beating the ear of the crop with stick. Animal trampling is treading a layer of 15 to $20 \mathrm{~cm}$ thick harvested crop by a team of animals followed by manual refining, depending upon capacity, lot size and situation. Threshing by animal treading is practiced on large scale in the country but it is also time consuming and involves drudgery. Animal trampling (hereafter referred as traditional) on average takes two human labor and 5 oxen for $10 \mathrm{hrs}$ to produce 1 tone output of fairly dried rice. However, it incurs huge loss due to spreading, fracture and mix up with soil impurities. Absence of sufficient livestock for trampling forces prolonging threshing period thereby increasing loss due to shattering, pests and rotting of grains. If threshing animals are not available, the farmers will thresh by stick beating little by little thereby exaggerating the loss.

\subsubsection{Pedal Rice Thresher}

The pedal thresher (Figure 1) consists of an open rotating drum with wire loops. The drum strips the grains from the panicles when fed by hand. The Pedal Rice thresher was simple to operate with leg muscle, doesn't consume fuel and it is used for threshing paddy rice easily. It can also be operated by women and can be used in hilly or terraced areas because of its portability [15].

Specification.

Power: human labor (chain drive mechanism).

Labor requirement: 2 persons.

Weight: $35 \mathrm{Kg}-40 \mathrm{Kg}$.

Dimension $\left(\mathrm{L}^{*} \mathrm{~W} * \mathrm{H}\right): 62 * 65 * 63 \mathrm{~cm}$.

Capacity: $110-120 \mathrm{Kg} / \mathrm{hr}$.

Threshing drum: peg type.

Peg diameter: $46 \mathrm{~cm}$.

Peg length: $44.5 \mathrm{~cm}$.

Construction material: steel metal.

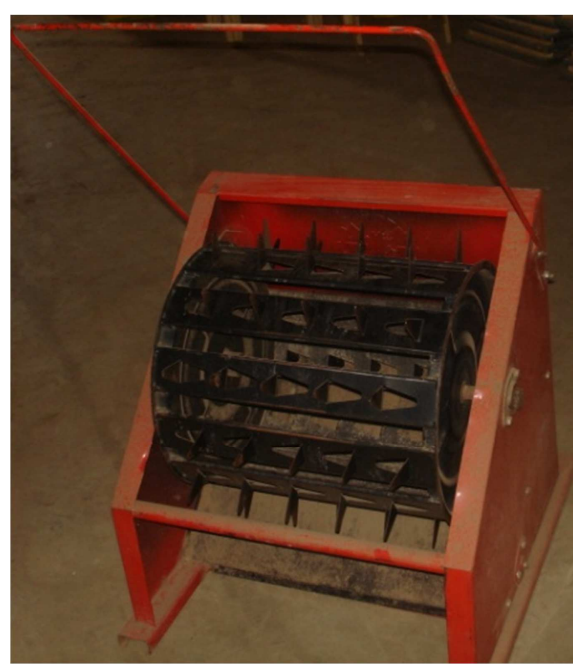

Figure 1. Imported thresher drum. 


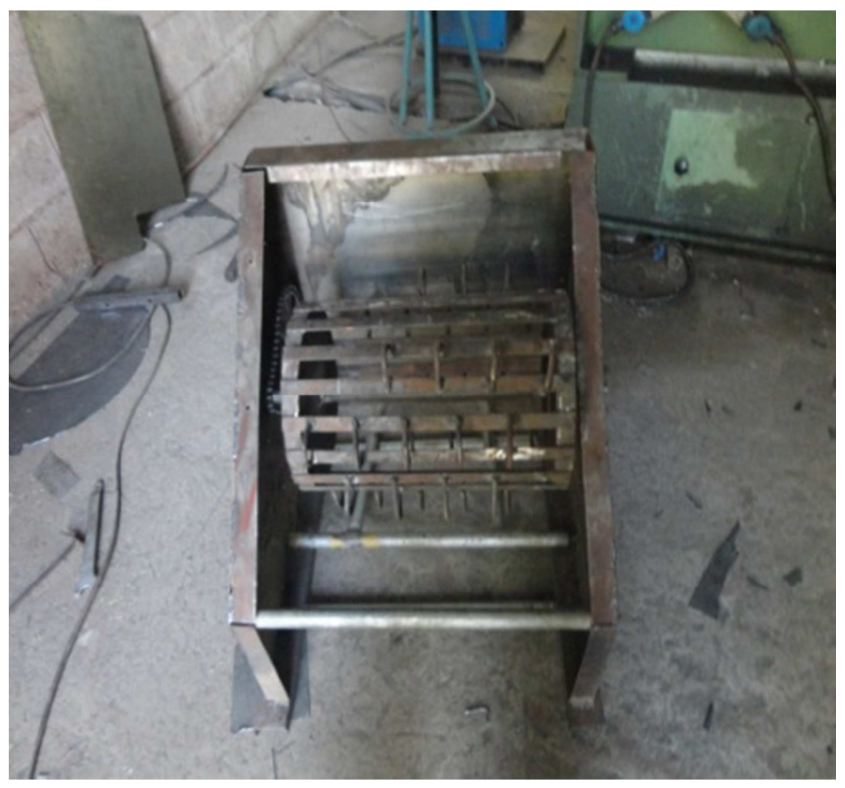

Figure 2. Modified thresher drum.

\subsubsection{Modified Thresher}

This thresher (Figure 2) was fabricated at the center using reverse engineering. After fabrication, the modified thresher was tested. Some modifications were introduced on the threshing drum and driving mechanism. The imported thresher was gear driven while the newly fabricated one was chain driven. This is because of unavailability of raw material to fabricate gear at the center. The threshing drum of the imported one was fabricated from thin sheet steel by special machine but the modified ones threshing drum was peg type fabricated from deformed iron because it was not possible to manufacture the imported threshing drum type by the existing machines in the metal work shop. All the other specifications are similar to the pedal type except the weight, which is slightly heavier.

\subsection{Data Collection and Analysis}

\subsubsection{Data Collection}

Samples were taken on the two threshers to measure their threshing efficiency and capacity. Opinions, views and response of the participants about the technology as compared with the traditional practice were collected. Threshing by the pedal type, the modified (Figure 3) and traditional methods were conducted using $X$-Jigina rice variety. The threshing was done for 10 minutes on each practice. Sample was collected from 5 trainees for pedal type and from 3 trainees for modified one in Shina-Tsion Kebele.

\subsubsection{Data Analysis}

Data was analyzed using SPSS, Stata 12 and Microsoft Excel softwares. Mean tests for the three type of threshers (traditional, pedal and modified) using Duncan and Tukey tests were conducted (Table 3 ).

\subsubsection{Financial Analysis}

For financial analysis (Table 4) a price tag of Ethiopian Birr (ETB) 4576.8 is assumed, including $10 \%$ labor cost and $10 \%$ profits for both the modified and the pedal threshers. A service life of 10 years with constant depreciation, 5000 working hours and maintenance cost of 7\% [16] is considered for the threshers. Thus, annually the thresher can be used for $500 \mathrm{hrs}$ and annual investment cost of ETB 457.68. A monthly interest rate of $5.5 \%$ is taken for the opportunity cost of cash of the farmers as most likely they will save it in the formal Banks, considered as the next best opportunity. Average farm gate price of Fogera rice is assumed ETB 12. Although equal price is set for both rice threshed by traditional and pedal threshers, in reality the price for rice threshed by either the pedal or the modified is expected to fetch better price due to better quality.

\section{Results and Discussion}

\subsection{Threshing Capacity}

The threshing capacity (Table-1) of the thresher depends on Paddy rice holding capacity of the operator at once with hand, feeding rate of the operator, threshing unit /drum rpm [14] and the variety of the rice and other factors. In addition, driving mechanism may influence the threshing capacity. Gear drive is more efficient than chain drive. The efficiency of gear drive was $99 \%$ while chain drive was 95\%. This difference in driving mechanism efficiency comes up to different rpm on the threshing drum. This enters influence the capacity of their threshing per hour. In this evaluation, beating rice heads with a stick/locally named as 'dula' has an average output of $92.04 \mathrm{Kg} / \mathrm{hr}$ (Table 1). The pedal operated has slightly higher output than the modified thresher.

Table 1. Pedal and traditional threshing performance ( $1^{\text {st }}$ year).

\begin{tabular}{lllllll}
\hline \multirow{2}{*}{ Test trial } & \multicolumn{2}{l}{ Pedal operated Rice thresher } & \multicolumn{3}{l}{ Traditional threshing by beating with stick/Dulla/ } \\
\cline { 2 - 7 } & $\begin{array}{l}\text { Testing time } \\
(\mathbf{m i n})\end{array}$ & $\begin{array}{l}\text { Threshing amount } \\
(\mathbf{K g})\end{array}$ & $\begin{array}{l}\text { Threshing capacity } \\
(\mathbf{K g} / \mathbf{h r})\end{array}$ & $\begin{array}{l}\text { Testing time } \\
(\mathbf{m i n})\end{array}$ & $\begin{array}{l}\text { Threshing amount } \\
(\mathbf{K g})\end{array}$ & $\begin{array}{l}\text { Threshing capacity } \\
(\mathbf{K g} / \mathbf{h r})\end{array}$ \\
\hline 1 & 10 & 24.25 & 145.5 & 10 & 17.40 & 104.40 \\
2 & 10 & 20.5 & 123.0 & 10 & 15.25 & 91.50 \\
3 & 10 & 20.0 & 120.0 & 10 & 14.25 & 85.50 \\
4 & 10 & 22.5 & 135.0 & 10 & 16.30 & 97.80 \\
5 & 10 & 19.00 & 114.0 & 10 & 13.50 & 81.00 \\
\hline
\end{tabular}




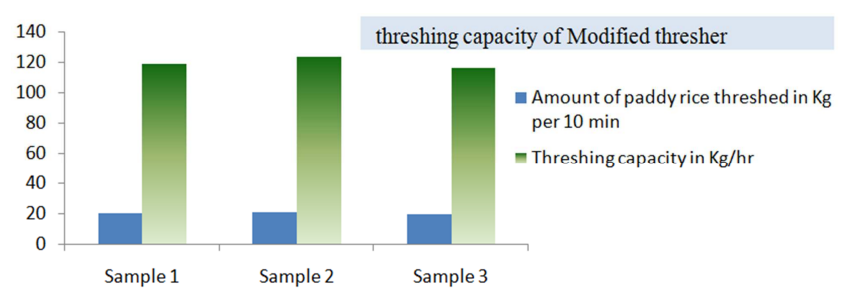

Figure 3. Threshing capacity for modified thresher ( $2^{\text {nd }}$ year $)$.

\subsection{Threshing Efficiency}

Spreading the rice panicles over the drum was essential for threshing efficiency. The person should seize a manageable size for accessing the beaters or else should turn the sides of the panicles and rotate to thresh. There is no paddy rice left over with the rice straw in the pedal as well as the modified one. Then in these scenarios, the threshing efficiency of the machine was $100 \%$ (Table 2).

Table 2. Average threshing capacity $(\mathrm{kg} / \mathrm{hr})$.

\begin{tabular}{llllll}
\hline \multirow{2}{*}{ Thresher type } & \multicolumn{2}{l}{ Mean } & Std. & Max & \multirow{2}{*}{ Min } \\
\cline { 2 - 4 } & Actual & At sensitivity * & Err & & \\
\hline Traditional & 92.04 & 82.8 & 4.19 & 104.4 & 81 \\
Modified & 119.6 & 107.64 & 2.12 & 123.6 & 116.4 \\
Pedal operated & 127.5 & 114.75 & 5.65 & 145.5 & 114 \\
\hline
\end{tabular}

*The sensitivity is considered at $10 \%$ down performance of individuals recognizing that humans are liable to fatigue and tiresome after working some length of time leading to a lower average performance per individual.

Breakage: samples taken from threshed paddy showed no broken seeds. In addition to experts, the farmers confirmed the absence of breakage. There was no paddy broken during threshing in both threshers. Therefore, paddy rice breakage was nil by both the machines.

Table 3. Statistical comparison of mean threshing capacity.

\begin{tabular}{|c|c|c|c|c|c|}
\hline \multirow{2}{*}{$\begin{array}{l}\text { Thresher } \\
\text { mean }\end{array}$} & \multicolumn{2}{|c|}{ Group\# } & \multirow{2}{*}{$\begin{array}{l}\text { Thresher } \\
\text { types }\end{array}$} & \multirow{2}{*}{ Contrast } & \multirow{2}{*}{ t-value } \\
\hline & Tukey & Duncan & & & \\
\hline Traditional & & & $\begin{array}{l}\text { Pedal Vs } \\
\text { modified }\end{array}$ & 7.9 & 1.07 \\
\hline Modified & $\mathrm{A}$ & A & $\begin{array}{l}\text { Modified Vs } \\
\text { traditional }\end{array}$ & 27.56 & $3.74 * * *$ \\
\hline Pedal & A & A & $\begin{array}{l}\text { Pedal Vs } \\
\text { traditional }\end{array}$ & 35.46 & $5.56 * * *$ \\
\hline
\end{tabular}

\#means sharing the same letter are not significantly different at $5 \%$ level; *** significant at $1 \%$ level of significance.

Overall analysis of the comparative evaluation of the technologies (Table-2) resulted in significant difference on the average output between the traditional method and the technologies demonstrated. The two most common three population group test statistics showed the absence of mean threshing difference between the pedal and the modified threshers. However, significant difference was observed on traditional thresher output compared to both modern technologies. Further a two group mean test showed the absence of significant threshing capacity difference between the pedal and the modified thresher. However, the capacity was significantly higher for both technologies compared to the traditional system at $1 \%$ level of significance.

\subsection{Farmers' Feedback}

Most of the farmers research extension group (FREG) member farmers thought that the pedal rice thresher is important because it does not break the straw into pieces. This helps to use the straw for house roof cover since grass is not available in the near place for this purpose. Farmers appreciated the easiness of the machine to transport by one person, to do threshing for daily consumption before threshing the whole harvest and easiness to operate by women and children. Farmers indicated that the modified is heavier than the pedal type. Transportation of both threshers by a single person was considered as an opportunity for utilization by the larger population, making it available to the inaccessible areas [15]. The threshing capacity of the modified was relatively less than the pedal one. Even though the thresher was better as compared to the traditional practice and has the above listed advantages; farmers showed less interest on it. This is due to priority of farmers problems. Paddy threshing is not a priority in the area. Natural shattering property of the crop is considered as an opportunity for not considering threshing a major issue. The farmers also indicated tediousness to work on it full day bases as a defect of the technology. However, with all family members capable of working it, it will not be a problem to work on it as there will be replacement when tired. On the other hand, farmers appreciated the technology for enabling threshing during peak working times and for small amounts in case of immediate household consumption needs by any member of the household.

Table 4. Financial analysis.

\begin{tabular}{lllll}
\hline Parameter & $\begin{array}{l}\text { Stick } \\
\text { beating }\end{array}$ & Traditional & Pedal & Modified \\
\hline $\begin{array}{l}\text { Output for 500hrs } \\
\text { (tons/yr) }\end{array}$ & 46 & 50 & 63.75 & 59.8 \\
$\begin{array}{l}\text { Income (ETB/yr) } \\
\text { Labor cost }\end{array}$ & 55200 & 60000 & 76500 & 71760 \\
(ETB/yr) & 2500 & 17500 & 5000 & 5000 \\
Cost of machine * & - & - & 870.15 & 870.15 \\
Maintenance cost & - & - & 32 & 32 \\
$(7 \%)$ & 17500 & 5902.15 & 5902.15 \\
Total cost (ETB) & 2500 & 42500 & 70597.9 & 65857.9 \\
\hline Net benefit (ETB) & 52700 & & \\
\hline
\end{tabular}

*It includes opportunity cost of investment within a year.

But threshing has its own effect on hulling [7] and the rice quality and hence requires proper threshing methods [8]. Extensive work to create awareness of the farmers on consequences of different threshing methods may enable adoption of the technologies.

Thus, a farmer having $0.35 \mathrm{ha}$ of rice land with a 
productivity of 3.16 tons/ha [17] can thresh his/her rice in 9.25hrs and $8.68 \mathrm{hrs}$ using the modified and the pedal threshers respectively. The cost of threshing will be less than ETB 100 in both of the threshers. If traditional threshing was used, it would have taken $12 \mathrm{hrs}$ and a cost of ETB 420.58 , without including the physical and quality losses incurred. Thus, for the rest of the season the farmer could use the thresher in the form of custom hiring. If 2ETB is levied on $1 \mathrm{hr}$ period of threshing, the custom hiring could help a farmer to recover the investment within only 4 harvesting seasons or years. The problems of threshing loss resulting in quantitative and qualitative loss that will be reflected in the market makes use of the traditional and stick beating threshing methods not preferable even without considering the financial benefits. Adoption of the threshers is a crucial fact that smallholder should consider for increasing their benefits and marketable yields.

\section{Conclusions}

The financial analysis showed that utilisation of pedal and modified rice threshers have a net benefit margin of ETB 28098 and ETB 23358 in the first year of investment. Fogera Woreda is one the most intensive agricultural production system where three to four crop productions are undertaken. The promotion and utilization of the modified rice thresher reduces the threshing labour demand of an average Fogera farmer by $77.08 \%$. Besides, farmers appreciated for home consumption and the avoidance of hay breakage used for thatching. However, they considered it as a low priority where weeding and planting are recently considered as major bottlenecks. However, inappropriate post harvest handling including threshing results in physical loss of produce and the produce becomes low quality resulting in low market competitiveness and low income for farmers. The feedbacks collected reflect none of this idea. This is due to low awareness by farmers that necessitates for awareness creation and subsequent promotion of the technology for wider adoption. Hence, wider scale promotion of the technology is paramount importance to increase adoption and subsequently enlarge households' income, marketable yield and hence increase national food availability and accessibility. This study lacks data on quality of rice by using the different threshing methods and the resulting market price to specific qualities. Hence, future promotions should consider these limitations and incorporate the physical and quality loss to bring to light the opportunities for adoption. Further, it could be advisable to see longer period experiments on the thresher as fatigue may decrease optimum threshing capacity of individuals.

\section{References}

[1] Gebey, T., Berhe, K., Hoekstra, D. and Alemu, B. 2012. Rice Value chain development in Fogera Woreda based on the IPMS Experience. Nairobi, Kenya: ILRI.

[2] Tilahun Tadesse, Nigussie Dechassa, Wondimu Bayu, Setegn Gebeyehu, 2013. Impact of Rainwater Management on
Growth and Yield of Rain fed Lowland Rice. Wudpecker Journal of Agricultural Research, 2 (4): 108-114.

[3] Yayeh Bitew and Fekremariam Asargew, 2014. Rice (Oryza Sativa) and Chickpea (Cicer aritinum L) Relay Intercropping Systems in an Additive Series Experiment in Rain Fed Lowland Ecosystem of Fogera Vertisols. Journal of Science Research, 2 (6): 179-184.

[4] Tilahun T., Alemayehu A., Minale L., and Zelalem T. 2008. Effect of Seed Soaking and Incubation on the emergence, Growth and Yield of Rice. In: Ermias A., Akalu T., Alemayehu A. G., Melaku W., Tilahun T., and Wondimu B. (eds). 2008. Procceedings of the 2nd Annual Regional Conference on Completed Crop Research Activities, 18-21 Sep. 2007. Amhara Regional Agricultural Research Institute. B. D., Ethiopia. Pp. 36-40.

[5] Ethiopian Institute of Agricultural (EIAR), 2011. Empowering Farmers' Innovation, Series No. 2: Challenges and Opportunities of Rice in Ethiopian Agricultural Development, Addis Ababa, Ethiopia.

[6] Kebebew Assefa, Dawit Alemu, Kiyoshi Shiratori and Abebe Kirub, 2011. Challenges and Opportunities of Rice in Ethiopian Agricultural Development. FRG II Project Empowering Farmers' Innovation. Series No. 2. EIAR - JICA Cooperation.

[7] Zewdu Ayalew, Abebe Fanta and Solomon Abera, 2013. Effect of Parboiling Treatment on the Milling Quality of Selected Rice Varieties. Journal of Postharvest Technology, 01 (01): 060-068.

[8] Appiah F, Guisse R. and Dartey P. K., 2011. Post Harvest Losses of Rice from Harvesting to Milling in Ghana. Journal of Stored Products and Postharvest Research, 2 (4): 64-71.

[9] Yemane Asmelash, 2014. Determinants of adoption of upland rice varieties in Fogera district, South Gondar, Ethiopia. Journal of Agricultural Extension and Rural Development, 8 (12): 332-338.

[10] Teshome Negussie and Dawit Alemu, 2011. An Overview of the National Rice Research and Development Strategy and its Implementation. In the Challenges and Opportunities of Rice in Ethiopian Agricultural Development. FRG II Project Empowering Farmers' Innovation Series No. 2.

[11] Manful J, Fofana M (2010). Postharvest practices and the quality of rice in West Africa. CORAF/WECARD. 2nd Science Week. 24-29 May, 2010, Cotounou, Benin.

[12] African Post Harvest Losses Information Systems (APHLIS), 2015. Rice Loss Tables Ethiopia: Estimated post harvest losses for 2003-2014. Accessed at www.aphlis.net/?form $=$ losses estimates\&co $\mathrm{id}=19 \& \mathrm{c}$ id $=32$ 7 on $24 / 07 / 2015$.

[13] Azouma, Y., Porosi M., and Yamaguchi K., 2009. Design of Throw-In Type Rice Thresher for Small Scale Farmers. Indian Journal of Science and Technology, 2 (9): 10-14.

[14] Selco Foundation, 2013. Testing of Small Scale Threshing Machines in Rural Karnataka. Accessed at www.selcofoundation.org/wp.../05/Threshing-Testing-FinalReport.pdf on 24/07/2015.

[15] Abdul Shakoor Khan and M. Salin, 2005. Rice Harvesting and Threshing. Pakistan Journal of Food Science, 15 (1-2): 45-52. 
[16] FAO, 2015. Grain Storage Techniques: Evolution and Trends in Developing Countries. Accessed at www.fao.org/docrep/t1838e/T1838E0r.htm on 8/11/2015.
[17] Astewul Takele, 2010. Analysis of Rice Profitability and Marketing Chain: The Case of Fogera Woreda, South Gondar Zone, Amhara National Regional State, Ethiopia. An MSC Thesis Submitted To Haramaya University. 